\title{
E.A. Parfitt, L. Wilson: Fundamentals of physical volcanology
}

\author{
Blackwell, Oxford, 2008. Paperback, 256 pages, ISBN: 978-0-632-05443-5
}

\author{
Brittany D. Brand
}

Received: 14 January 2010 / Accepted: 20 January 2010/Published online: 9 February 2010

(C) Springer-Verlag 2010

Fundamentals of Physical Volcanology is an advanced textbook that details the control of subsurface magmatic processes on the style and explosivity of volcanic eruptions. The authors use basic physics to explain the mechanisms behind magma generation, movement, and eruption. Processes are broken into stages including generation of magma, magma movement in the mantle and crust, magma storage, magma movement in the shallow crust, and volcanic activity. Several chapters are also dedicated to volcanic hazards, monitoring, volcanoes and climate, and planetary volcanology resulting in a comprehensive resource for processes and consequences of volcanic activity.

The application of basic physics to understand subsurface and subaerial volcanic processes provides a more quantitative foundation than traditional volcanology texts. A prior knowledge of petrologic processes and classification of igneous rocks is assumed. Thus students who have not taken a basic petrology course may need supplemental material to reach the expected level of understanding. In addition, the authors focus more on the control of subsurface processes on eruption style and dynamics, thus chapters addressing the physical processes and nature of eruptions and their materials (e.g., lava flows, pyroclastic processes) are less involved and have fewer figures than traditional volcanology texts.

This book is aimed towards an upper-level audience, such as research volcanologist or instructors and students in upper-level volcanology or physical volcanology courses. The book is well-organized, well-written, and contains figures and captions that provide sufficient visual support for the subject matter. Thought provoking questions are supplied at the end of each chapter, which highlight information from each topic that inspire critical thinking. In addition, references are separated by subject allowing the reader to easily identify supporting material for a given subject matter. It is affordable and provides a great resource for students and researchers alike to develop a more quantitative understanding of physical volcanological processes. 